\title{
Breaking the Silence and Healing Trauma for Incarcerated Women: Peer-facilitated Delivery of a Brief Intervention
}

\begin{abstract}
Peer-facilitated programs in corrections can be a cost-effective strategy to provide more opportunity for program services in prison. Brief interventions are also a valuable way to introduce programs to those assigned to short-term housing, while preparing them for lengthier programming once placed in permanent housing. The usefulness of brief interventions in substance use treatment has been extensively researched in the literature; however, the evidence regarding peer-facilitated programs with a trauma focus is less available. Given the extensive prevalence of lifelong trauma in the lives of justice-involved women, there is a vital need for trauma-specific interventions and research assessing both content and models of delivery. This pilot study assesses the effectiveness of a brief peerfacilitated, trauma-specific intervention among participants incarcerated at two women's facilities in California. Healing Trauma ${ }^{1}$ is a 6-session brief intervention that was designed for women who have experienced trauma associated with adverse childhood experiences. The peer-facilitated intervention was delivered twice a week with two-hour long sessions in closed groups of $6-8$ participants. The sample consisted of 682 participants who volunteered for the program and study. Data were collected prior to the start of the first session and upon completion of the last session on ten primary outcomes: depression, anxiety, PTSD, mental health symptoms, aggression, anger expression, anger representation, empathy, social connectedness, and emotional regulation. The results demonstrated strong support for the efficacy of Healing Trauma and a peer-facilitated model of program delivery. Participants exhibited significant improvement across $90 \%$ of the outcomes measured. Effect sizes were small to moderate in size, with the largest impact on depression, PTSD, and feelings of anger (Cohen's $\mathrm{d}$ ranged from $.51, .41, .42$ respectively). The findings provide a knowledge base to create more rigorous studies for further exploration of outcomes.
\end{abstract}

Keywords: Adverse childhood experiences, trauma-specific, peer-facilitation, brief interventions, corrections
Volume 10 Issue I - 202I

\author{
Nena Messina,' Elizabeth Zwart ${ }^{2}$ \\ 'Envisioning Justice Solutions, Inc, USA \\ ${ }^{2}$ Harvard Kennedy School MPP candidate and Harvard Business \\ School MBA candidate, USA
}

\begin{abstract}
Correspondence: Nena Messina, UCLA Integrated Substance Abuse Programs Criminal Justice Research 11075 Santa Monica Blvd., Suite 200, Los Angeles, CA 90025, Tel 3108018996 ,
\end{abstract} Emailnmessina@g.ucla.edu

Received: December 04, 2020 | Published: Janauary 26, 2021

\section{Introduction}

Two decades of literature outlines a high prevalence of adverse childhood experiences (ACEs) such as physical abuse, sexual abuse, and household dysfunction (e.g., incarceration of a parent, violence, substance use, and mental illness in the home) among incarcerated women. ACEs reported among justice-involved women have been retrospectively linked to an increased likelihood of adolescent conduct disorder, teen pregnancy, homelessness, substance use/dependence, early criminal activity, prostitution, and violence in adolescent and adult relationships. ${ }^{2-5}$

Furthermore, childhood trauma is highly correlated with adult mental health issues, increased likelihood of incarceration, ${ }^{6-8}$ and female-perpetrated violence. ${ }^{9-12}$ Abuse and violence often continue for women while in custody, with women potentially suffering sexual and physical abuse from interpersonal relationships they have formed in prison, from conflict with other residents, and from custody officers. ${ }^{13-14}$ Thus, the violence and trauma experienced in women's childhood, adolescence, and adult life often continues in their custodial life.

The corrections field has recently begun to better understand the critical role of ACEs in mental health, anger, aggression, and conflict. The California Department of Corrections and Rehabilitation (CDCR) recognizes that it is imperative to provide trauma-focused programs to address antisocial behaviors while creating a safe environment for both staff and residents. In 2019, the CDCR mandated the provision of manualized, gender-responsive, and trauma-focused substance use programs consistently across all 35 California prisons substance use programming yards (i.e., Helping Men Recover and Helping Women Recover $).{ }^{15,16}$ However, trauma-focused programs in other corrections environments (e.g., security housing or the general population yards) remain sparse throughout the nation.

Previous research has shown that trauma-informed and genderresponsive programs can be effectively implemented for incarcerated people beyond those primarily in programs for substance use disorders. ${ }^{17-20}$ Yet too often program participation in the general population prison environment can be interrupted by temporary placement and institutional movement (e.g., a prison reception center, security housing units, and temporary mental health housing). Short-term housing significantly reduces access to program services available to those in the general prison population. One alternative to address barriers of frequent resident movement in a prison is the use of brief interventions.

The current study assesses the impact of a 6-session, brief, traumaspecific intervention designed for women who have experienced trauma and violence associated with ACEs and adult victimization 
(i.e., Healing Trauma: A Brief Intervention for Women) ${ }^{1}$. The program was implemented using a peer-facilitated model throughout two women's prisons in California, with the goal of increasing overall mental health functioning and reducing anger and aggression.

\section{Brief interventions}

Brief interventions and brief therapies have become increasingly well known in the field of addiction. The literature has outlined effective brief interventions for people with substance use disorders and those at most risk to develop them. ${ }^{21}$ Policymakers and clinicians have increasingly focused on brief interventions as a cost-effective strategy to fill the gap between primary prevention efforts and more intensive substance use treatment. Brief therapies have also been implemented in the field of substance use and psychotherapy. In this context, interventions that range from 12 to 40 sessions are considered brief. The evidence regarding brief trauma-specific interventions implemented in custody settings is considerably sparse. However, a large randomized controlled trial including a sample of 1,573 incarcerated men from 20 facilities tested 6 brief interventions created by Texas Christian University (i.e., Targeted Intervention for Corrections - TIC). Findings showed significant improvement in knowledge, attitudes, and psychosocial functioning. Improvements were less consistent for criminal thinking; however, the authors concluded that overall the evidence supported the efficacy of brief interventions in a custody setting. ${ }^{22}$

There are prime opportunities for brief trauma interventions. There are areas of prison housing that are reserved for short stays (e.g., reception centers, security housing units, and specialty housing units). Historically, a prison reception center is dedicated to assessment, classification, and placement (up to 90-120 days). The relatively short stay is an opportunity to provide residents necessary exposure to effective programs and encourage continued program participation upon final placement. Another short stay housing environment is the special housing units for high need populations (e.g., those demonstrating behavioral problems, reoccurring infractions, and refusal to participate in work or program services). Many of the residents moved to these housing units are challenged with mental illness. Thus, residents in short-stay housing units can be amenable to the delivery of brief trauma interventions to address some of the behavioral needs and complications prior to placement in the facilities general population.

\section{Peer-facilitation}

"Mentors" have frequently been a resource to assist in the delivery of substance use programs, health education (e.g., cancer, HIV, or other chronic illness), and in the juvenile justice system. ${ }^{23-25}$ This model has also been implemented in adult correctional settings. ${ }^{26,27}$ Peer-facilitators are often those serving long or life sentences who have volunteered to mentor other residents or facilitate programs (e.g., Alcoholics Anonymous, Narcotics Anonymous, and anger management). Peer-facilitated programs can often be scheduled group gatherings without a formal topic of focus and rarely allow for rehabilitative achievement credits or milestone credits (e.g., time off from a sentence). Research assessing the impact of programs with extensive peer training, staff coordination and oversight, facilitator guides and manualized curricula is limited.

An expert symposium conducted on the efficacy of peerfacilitated programs in prison concluded that peer facilitation can improve health outcomes, with a positive impact for both facilitators and participants. ${ }^{28} \mathrm{~A}$ systemic review of the effectiveness of peer education in prisons also supported the positive impact of this delivery model. ${ }^{26,29}$ Using a randomized controlled trial, Messina and Calhoun ${ }^{20}$ assessed a peer facilitated 20 -session trauma-specific intervention (i.e., Beyond Violence, Covington, 2014) among 123 incarcerated women in California. The peer-facilitators were trained by the program author and provided with a step-by-step facilitator guide and participant workbooks. Findings showed that Beyond Violence participants had significantly lower mental health, anger/ aggression, and emotion dysregulation scores at the post-intervention assessment when compared to the control group. The randomized controlled trial substantiated the findings from the earlier pilot study. ${ }^{17}$

\section{Theoretically based treatment}

The current study follows the principles of trauma theory. Traumaspecific programs are typically grounded in trauma theory. Trauma theory suggests that early trauma influences both perceptions of and reactions to life events..$^{30-32}$ Moreover, trauma exposure, particularly early and ongoing, may result in mental health disorders, ${ }^{33,34}$ the use of alcohol/drugs, ${ }^{35,36}$ and repressed anger. ${ }^{37-39}$ Anger from trauma is theorized to be confounded with emotional pain and often lacks healthy expressions, leading to the continual repression of anger and pain that may result in assaultive and violent behavior. ${ }^{40}$ There is a growing body of literature outlining the positive impact of theoretically based, trauma-specific programs for incarcerated women with substance use disorders, co-occurring mental health issues, ${ }^{18,41}$ and histories of violence. ${ }^{17,20,42,43}$

This current study builds on this body of research and assesses the effectiveness of a brief 6-session trauma-specific intervention led by peer-facilitators to reduce trauma-related mental health difficulties and aggressive behaviors among incarcerated women housed in the general prison population.

\section{Methods}

Evaluation approvals were obtained from the Office for Human Research Protections and the California Department of Corrections and Rehabilitation's Research Oversite Committee prior to any contact with participants. The study began in July of 2017 and data collection ended in June 2019.

\section{Program description}

Healing trauma: A Brief Intervention for Women ${ }^{l}$ is a trauma-specific intervention designed for women who have experienced trauma and violence associated with ACEs and adult victimization. Healing Trauma $(H T)$ is based in trauma and relational-cultural theory and is designed for delivery in settings in which a short-term intervention is needed. It is comprised of six, 2-hour sessions meant for closed groups of up to $6-8$ women. There is a Facilitator Guide and Participant Workbook for each session. The $H T$ intervention focuses on three core elements:

1) An understanding of what trauma is,

2) Its process, and

3) Its impact on both the inner self (thoughts, feelings, beliefs, values) and the outer self (behavior and relationships).

The $H T$ curriculum includes a variety of therapeutic approaches: cognitive behavioral therapy (CBT), expressive arts, mindfulness, and guided imagery. $H T$ is currently considered to be at a 'best practices' 
stage of evidence. A recent pilot study was completed on a sample of 39 women in the security housing unit. ${ }^{20} H T$ was facilitated by trained professionals at the facility and research staff administered pre- and post-intervention surveys. Participants exhibited significant improvement across depression, anxiety, PTSD, aggression, anger and social connectedness. Effect sizes were moderate to large, with the largest impact on physical aggression (Cohen's d ranged from 0.39 to 0.82 ).

\section{Hypothesis}

Based on the results of studies that tested the impact of longer $(20+$ session) gender-responsive and trauma-specific interventions for women ${ }^{17,18,41,42}$ and the positive results from the pilot study from the security housing participants, it was hypothesized that a brief traumaspecific intervention (HT) would lead to significant improvement on the mental health and anger/aggression outcome measures among participants in the general prison population.

\section{Peer facilitators}

The $H T$ program was facilitated by peer mentors who received two days of training by Dr. Covington, the author of HT. Peer mentors in the California prison system are chosen to provide education, support, or other advice to residents with the facility. Peer mentors also complete an orientation for newly incarcerated women. The peer mentors chosen for this pilot study were interviewed by the $H T$ Program Coordinators and were referred to as "Peer-Facilitators". The criteria for selection included having the ability to connect with other residents, having social influence, previously holding positions as mentors, and being available during programming hours. All Peer Facilitators were required to participate in $H T$ as participants before facilitating the program to others. Facilitation of $H T$ was a facilityfunded paid position. The Peer-Facilitators were women serving life without parole or long-term offenders serving more than 10 years (the majority were incarcerated for homicide - 66\%). On average, peer facilitators were 43.6 years old (s.d. $=10.59$ ), and had been incarcerated an average of 16.4 years, (s.d. $=7.74$ ). Thirty-two percent the facilitators were Black, $27 \%$ were White, $19 \%$ were Latina, and $22 \%$ were multiracial. Over two-thirds completed some college, and a quarter held a college degree. Facilitators reported 6.5 ACEs on average, ranging from 1 to 10 .

\section{Participants}

This study combines data collected from 916 participants in the $H T$ program in two California prisons. Participants in this study were not asked about their gender identity; while we use the word women to refer to our participants, some participants may hold other gender identities. The participants at Prison 1 were women who were considered to be those with high needs and high risk of problematic behavior (e.g., refused to participate in other programs, several infractions within the past year, arguing with staff, refusing to leave housing unit, refusing to get dressed, etc.). The participants at Prison 2 were women who were housed in the reception center waiting to be assessed for housing placement within the facility.

Flyers about the program were posted in the housing units and any woman could sign up to participate in the program. Facility staff provided access to those who signed up prior to the first session of $H T$. Research staff explained the study, answered questions, and had those agreeing to participate sign the informed consent form. The research staff member read the consent form to the participants describing the study, the measures used to protect the confidentiality of the responses, and the voluntary nature of the study. There were no ineligibility criteria; however, they were required by the facility to complete 5 of the 6 sessions to graduate. They could participate in the program and decline to participate in the evaluation with no penalty.

\section{Data collection}

Research staff provided the self-administered surveys at each facility prior to the $H T$ program entry. On average, the pre-survey was completed within 45 minutes. The post-survey took place after completion of the 6 sessions of $H T$ (approximately 3 weeks) and also took approximately 45 minutes to complete. Participants were not compensated for their participation in the $H T$ program or survey. A total of 916 women participated in the $H T$ program over the course of 2 years and 682 of those women completed the post-program survey ( $75 \%$ follow-up rate). However, 70 participants were unable to be reached for follow-up surveys because they left the facility (creating an adjusted follow-up rate of $81 \%$ ). ${ }^{1}$ Of those 70 participants, most (58) were transferred to another prison, and others were paroled, released from court, or otherwise no longer in the system. Demographics are shown for all 916 participants and the pre- and post- intervention results are conducted on the 682 women who completed both the pre- and post-program surveys. Of the 682 women in the final sample, $86 \%$ completed 5 or more sessions.

\section{Measures}

To assess the effectiveness of the $H T$ program, data were collected during the pre- and post-surveys on a variety of measures. Standardized instruments included detailed questions about demographics, childhood and adult trauma, mental health, substance use, and criminal justice involvement. The feasibility of these measures and procedures were previously found to be effective and valid. ${ }^{44}$

Depression (Patient health questionnaire - depression subscale): The Patient Health Questionnaire Depression Subscale is a 9-item subscale that measures current depressive symptomology. ${ }^{45,46}$ Participants report on the symptoms they have experienced in the preceding two-week period. Responses are based on a 4-point Likerttype scale ranging from 0 (Not at all) to 3 (Nearly every day) and are summed into an overall symptom severity scale score that falls between 0 and 27 .

Anxiety (Patient health questionnaire - anxiety subscale): The Patient Health Questionnaire Anxiety Subscale is a 6-item subscale that measures anxiety symptoms felt over the past four weeks. ${ }^{46}$ Responses are based on a 4-point Likert-type scale ranging from 0 (Not at all) to 3 (Nearly every day) and are summed into an overall symptom severity scale score that falls between 0 and 18 .

PTSD (Short screening scale for DSM-IV PTSD (modified version): The modified version of the Short Screening Scale for DSMIV Posttraumatic Stress Disorder ${ }^{47}$ is used to assess current symptoms of PTSD. Respondents who responded affirmatively to the question "In your life, have you ever had any experience that you considered frightening, horrible, or upsetting?" were then asked to complete a 7-item Short Screening Scale, concerning symptom frequency in the

${ }^{1}$ Demographics for those who completed post-surveys were compared to those lost at follow-up. The two groups did not differ on basic demographic variables. However, those who completed the post-survey were significantly more likely to report verbal, physical, and sexual abuse under the age of 18 . The two groups did not significantly differ on total number of ACEs reported. 
prior four-week period. Item responses were based on a Likert-type scale, ranging from 0 (Not at all) to 3 (Nearly every day), and scale scores ranged from 0 to 21 .

K6 brief mental health screen: The K6, a 6-item brief mental health screening tool, ${ }^{48,49}$ was used to assess participant's overall mental health. Responses, based on a Likert-type scale, ranging from 0 (None of the time) to 4 (All of the time), were summed into an overall scale with scores ranging from 0 to 24 , with higher scores indicating a less healthy state of mental health.

Aggression (Buss-Warren aggression questionnaire (AQ): BussWarren Aggression Questionnaire (AQ), formally the Buss Perry Aggression Questionnaire, is a 34-item instrument used to assess anger and aggression. ${ }^{50}$ The respondent rates the description on a Likerttype scale, ranging from 1 (Not at all like me) to 5 (Completely like me). The Buss-Warren includes five sub-scales: Physical Aggression (8 questions 8 - 40 range), Verbal Aggression (5 questions, 5 - 25 range), Anger ( 7 questions, 7 - 35 range), Hostility ( 8 questions, 8 40 range), and Indirect Aggression (6 questions, 6 - 30 range).

State-Trait anger expression inventory-2 (STAXI-2): The STAXI-2 is a 57 -item instrument used to measure the experience and intensity of anger as an emotional state (State Anger) and as an emotional trait (Trait Anger). The State Anger Composite Scale assesses the intensity of angry feelings at a particular time and the Trait Anger Composite Scale measures how angry emotions are expressed over time. ${ }^{51}$ For the 15 State Anger items, participants rate the intensity of their emotions "right now" on a 4 point Likert scale ranging from 1 (Not at all) to 4 (Very much so). For the 10 Trait Anger items, participants rate how they 'generally' feel on a 4 point Likert scale ranging from 1 (Almost never) to 4 (Almost always). For the 32 Anger Expression and Anger Control items, participants rated how they generally react in certain situations also on a 4 point Likert scale ranging from 1 (Almost never) to 4 (Almost always).

Anger (Rev instrumental and expressive representation scales): The Revised Instrumental and Expressive Representation Scales have 16 items with 2 sub-scales (instrumental and expressive) assessing anger expression..$^{52}$ Instrumental anger is a more outward expression of anger that is often used to control others. In contrast, expressive anger is characterized by holding in or suppressing anger until there is an "explosion" of emotion. In the first subscale respondents answered the degree of agreement about 8 items measuring instrumental anger, including "I believe that physical force is needed to get through to some people" and "If I hit someone and hurt them, they were asking for it." The second subscales assessed expressive anger using 8 items such as "During a physical fight I feel out of control" and "After a physical fight I feel drained and guilty." Participants responded on a scale from 1 (Strongly Disagree) to 5 (Strongly Agree). Some items were reverse scored so that higher scores indicate stronger anger expression. The eight items from each subscale are summed with a range of $8-40$ for each sub-scale.

Resilience (The brief resilient coping scale): The BRCS is a brief 4-item, unidimensional measure designed to capture to what extent an individual copes with stress in a resilient fashion. ${ }^{53}$ Participants responded on a scale from 1 (Does not describe me at all) to 5 (Describes me very well) and total summed scores range from 4 to 20 . Higher scores indicate increased resilience.

Empathy (Interpersonal reactivity index): The Interpersonal Reactivity Index ${ }^{54,55}$ is a measure of dispositional empathy. The instrument contains four 7-item subscales, each tapping a separate facet of empathy, of which two were scored. The perspective taking (PT) scale measures the reported tendency to spontaneously adopt the psychological point of view of others in everyday life (e.g., "I sometimes try to understand my friends better by imagining how things look from their perspective"). The empathic concern (EC) scale assesses the tendency to experience feelings of sympathy and compassion for unfortunate others (e.g., "I often have tender, concerned feelings for people less fortunate than me"). Participants responded on a scale from 1 (Does not describe me at all) to 4 (Describes me very well) with some items reverse scored. Scores were summed with a range of $7-28$ for each sub-scale.

Social connectedness (Social connectedness scale-revised): The Social Connectedness Scale-Revised assesses experiences of closeness in interpersonal contexts, as well as difficulties establishing and maintaining a sense of closeness as evidenced by a mean item score equal to or less than 3.5. ${ }^{56,57}$ The scale consists of 20 items that are scored on a scale of 1 (Strongly Disagree) to 6 (Strongly Agree). The score is represented as a mean item score with range $1-6$.

Emotional regulation (Difficulties in emotion regulation scale): The DERS is a 36-item multidimensional self-report measure assessing individuals' characteristic patterns of emotion regulation. It contains six subscales that were theoretically formulated and confirmed through factor analysis. Responses made on a Likert scale ranging from 1 (Strongly Agree) to 6 (Strongly Disagree). Mean scale score $=88.02$ standard deviation $=16.82 .^{58}$ The six subscales are: Nonacceptance of Emotional Responses; Difficulties Engaging in Goal-Directed Behavior; Impulse Control Difficulties; Lack of Emotional Awareness; Limited Access to Emotion Regulation Strategies; Lack of Emotional Clarity.

\section{Statistical analysis}

Demographic characteristics: Initial analysis included descriptive and inferential statistics based on the reported background characteristics of participants. Descriptive statistics included percentages, means, and measures of variance. Frequency tables were used to examine cell sizes for categorical variables and non-normality for continuous variables. Where categorical variables had small cell sizes, categories were collapsed to create cells of sufficient size.

Efficacy of intervention: The second stage of data analyses were designed to quantify the efficacy of the HT brief intervention. Pairedsample $t$-tests were conducted to assess changes in the main outcomes across time (post-test scores minus pre-test scores), allowing for the examination of mean change over time per individual as well as the findings for the group as a whole. Cohen's d was computed to determine the effect size of significant treatment effects. ${ }^{59}$

\section{Demographics}

Prior to receiving the $H T$ programming, each participant selfreported characteristics such as their ethnicity, marital status, age, education level, arrest history, drug and alcohol use history, and childhood and adulthood experiences with trauma (Tables 1-3). Demographics for the participants from both facilities are combined and outlined below. Participant characteristics were initially analyzed separately, and a few characteristics showed significant differences between the group). Participants from the reception center (Prison 2) were significantly younger than those from the high need population at Prison $1(x=36, s . d .=9.63$ vs $x=40, s . d .=12.16)$; reported less ACEs $(x=4.6, s . d .=2.84$ vs $x=5.3$, s.d. $=2.83)$; and had not been incarcerated as long $(x=5.0$, s.d. $=5.79$ vs $x=10.8$, s.d. $=8.46)$. 
Table I Participant Demographics $(n=916)$

\begin{tabular}{|c|c|c|c|}
\hline Description & $\%$ & Mean & SD \\
\hline \multicolumn{4}{|l|}{ Race/Ethnicity } \\
\hline Latina/Hispanic & $34.10 \%$ & & \\
\hline White & $28.80 \%$ & & \\
\hline Black & $17.90 \%$ & & \\
\hline Multi-racial and other & $19.20 \%$ & & \\
\hline \multicolumn{4}{|l|}{ Marital Status } \\
\hline Never married & $45.00 \%$ & & \\
\hline Married or living together & $29.40 \%$ & & \\
\hline Divorced/separated/widowed & $25.60 \%$ & & \\
\hline Current Age & & 36.6 & -10.45 \\
\hline \multicolumn{4}{|l|}{ Education prior to incarceration } \\
\hline No high school degree & $36.50 \%$ & & \\
\hline High school degree/GED & $23.50 \%$ & & \\
\hline Some higher education & $40.00 \%$ & & \\
\hline
\end{tabular}

Table 2 Criminal Justice and Substance Use Histories $(n=916)$

\begin{tabular}{lll}
\hline Description & Mean & SD \\
\hline Age of first arrest & 21.5 & -9.32 \\
Lifetime arrests & 13.8 & -21.68 \\
Total years incarcerated & 6.5 & -7.04
\end{tabular}

Used alcohol or drugs during the 12 months prior to current incarceration?

$88.40 \%$

Frequency of alcohol use prior to arrest $(\mathrm{n}=810)$

2-3 times per week/nearly every day

$31.60 \%$

Every day

Frequency of drug use prior to arrest ( $\mathrm{n}=810$ )

2-3 times per week/nearly every day

$29.50 \%$

Every day

Substances used the 12 months prior to current incarceration $(n=810)$

Alcohol

Amphetamines / meth

$60.30 \%$

Marijuana

$50.60 \%$

Prescription Drugs

$18.50 \%$

Heroin / opiates

$17.90 \%$

Cocaine

$14.30 \%$

Designer Drugs

$8.40 \%$

Hallucinogens
Table 3 Childhood and Adult Abuse \& Mental Health Histories $(n=916)$

\begin{tabular}{|c|c|c|c|c|}
\hline \multicolumn{2}{|c|}{ Description } & $\%$ & Mean & SD \\
\hline \multicolumn{5}{|c|}{ Adverse Childhood Experiences } \\
\hline I. & Verbal abuse & $58.50 \%$ & & \\
\hline 2. & Sexual abuse & $51.20 \%$ & & \\
\hline 3. & Physical abuse & $53.90 \%$ & & \\
\hline 4. & Emotional neglect & $53.90 \%$ & & \\
\hline 5. & Physical neglect & $24.00 \%$ & & \\
\hline 6. & Parents separated or divorced & $68.90 \%$ & & \\
\hline 7. & Mother treated violently & $38.30 \%$ & & \\
\hline 8. & $\begin{array}{l}\text { An alcohol / drug user in the } \\
\text { household }\end{array}$ & $61.30 \%$ & & \\
\hline 9. & $\begin{array}{l}\text { Someone mentally ill or suicidal } \\
\text { in household }\end{array}$ & $37.20 \%$ & & \\
\hline & $\begin{array}{l}\text { An incarcerated household } \\
\text { member }\end{array}$ & $38.40 \%$ & & \\
\hline \multicolumn{2}{|c|}{ Total ACEs } & & 4.8 & -2.85 \\
\hline \multicolumn{5}{|c|}{ Adult Experiences of Victimization } \\
\hline \multicolumn{2}{|c|}{$\begin{array}{l}\text { Minor physical abuse (pushing, } \\
\text { slapping, restraining) }\end{array}$} & $79.40 \%$ & & \\
\hline \multicolumn{2}{|c|}{$\begin{array}{l}\text { Severe physical abuse (burning, } \\
\text { choking, stabbing) }\end{array}$} & $78.10 \%$ & & \\
\hline \multicolumn{2}{|c|}{ Intimidation } & $73.40 \%$ & & \\
\hline \multicolumn{2}{|c|}{ Forced sex } & $39.70 \%$ & & \\
\hline \multicolumn{2}{|c|}{ Ever diagnosed with a mental illness } & $61.40 \%$ & & \\
\hline
\end{tabular}

Demographic tables combine the baseline samples from the two prisons. Of the 916 women who participated in the $H T$ program, over two thirds are women of color, almost half have never been married, the average age was 37 , and over a third did not graduate from high school. Most also have a significant history of involvement with the justice system, and average age of first arrest was 22. Participants were incarcerated for a variety of offenses with theft/robbery $(28 \%)$, assault (14\%), homicide/murder/manslaughter (13\%), and drugs (13\%) most common. On average, participants had been arrested 14 times, and spent 7 years incarcerated. Of the 810 women who reported using alcohol or drugs in the 12 months prior to incarceration, almost three-fourths met criteria for substance use disorder and almost half met criteria for alcohol use disorder. Of substances used, alcohol (73\%) and amphetamines (60\%), and marijuana (51\%) were the most common, with over half of the women who used substances, using these in the 12 months prior to incarceration.

Prior to incarceration many women have had complex histories of trauma and household dysfunction. The women surveyed had experienced over 4 ACEs on average, with experiences of parental separation / divorce (69\%), alcohol or drug abuse in the household $(61 \%)$, verbal abuse $(59 \%)$, emotional neglect $(54 \%)$, physical abuse $(54 \%)$, and sexual abuse (51\%) impacting over half of the women. 
For most of the women, abuse in their adult lives was also common, with over $79 \%$ experiencing minor physical abuse, $78 \%$ experiencing severe physical abuse, and $73 \%$ experiencing intimidation as an adult. Forty percent of the women reported experiencing forced sex as an adult. Over $60 \%$ of women had been previously diagnosed with a mental illness.

\section{Results}

Table 4 summarizes the results of 682 women who participated in the $H T$ program and completed both pre- and post-survey evaluations. The hypothesis was supported as participants showed statistically significant improvement on 26 of the $29(90 \%)$ outcome measures analyzed. Specifically, there were statistically significant reductions in anxiety, depression, PTSD, general mental health symptoms, aggression, anger expression (7 of 9 measures), and anger representation (both measures). Furthermore, there was a significant increase in empathy (1 of 2 measures), social connectedness, and emotional regulation. Significant effect sizes were small to moderate in size (Cohen's d range of .083 to .510), with the largest impacts on depression (.51), PTSD (.41), and angry feelings (.42). There were not significant findings for measures within anger expression (trait anger - control out, trait anger- control in); however, both approached significance. Perspective taking, a sub-measure of empathy was also not significant.

Table 4 Results for Healing Trauma Participants ( $N=682$ )

\begin{tabular}{|c|c|c|c|c|c|}
\hline Description & Pre-Program Mean (SD) & Post-Program Mean (SD) & Change & Sig. & Cohen's d \\
\hline Anxiety & $5.4(4.53)$ & $3.9(4.02)$ & -1.5 & $\mathrm{P}<.00 \mathrm{I}$ & 0.348 \\
\hline Depression & $7.6(5.99)$ & $4.7(5.13)$ & -2.8 & $\mathrm{P}<.00 \mathrm{I}$ & 0.51 \\
\hline PTSD & $6.2(5.21)$ & $4.2(4.38)$ & -2 & $\mathrm{P}<.00 \mathrm{I}$ & 0.41 \\
\hline Mental Health Symptoms & $6.2(5.88)$ & $4.4(4.87)$ & -1.8 & $\mathrm{P}<.00 \mathrm{I}$ & 0.375 \\
\hline \multicolumn{6}{|l|}{ Aggression } \\
\hline Physical Aggression & I 7.4 (7.89) & $15.3(7.15)$ & -2.1 & $\mathrm{P}<.00 \mathrm{I}$ & 0.347 \\
\hline Verbal Aggression & II.4 (4.3I) & $10.6(4.15)$ & -0.8 & $\mathrm{P}<.001$ & 0.203 \\
\hline Anger & $14.8(6.28)$ & I $3.4(5.55)$ & -1.3 & $\mathrm{P}<.00 \mathrm{I}$ & 0.301 \\
\hline Hostility & I $7.8(7.04)$ & -6.63 & -1.8 & $\mathrm{P}<.00 \mathrm{I}$ & 0.303 \\
\hline Indirect Aggression & $12.6(4.78)$ & II.4 (4.5I) & -1.2 & $\mathrm{P}<.00 \mathrm{I}$ & 0.276 \\
\hline \multicolumn{6}{|l|}{ Anger Expression } \\
\hline State Anger Feelings & $2.4(3.34)$ & $1.0(2.05)$ & -1.4 & $\mathrm{P}<.001$ & 0.417 \\
\hline State Anger Verbal & $1.9(3.45)$ & $1.2(2.62)$ & -0.7 & $\mathrm{P}<.001$ & 0.2 \\
\hline State Anger Physical & $0.9(2.45)$ & $0.6(1.95)$ & -0.3 & $\mathrm{P}<.004$ & 0.111 \\
\hline State Anger Composite Score & $5.3(8.40)$ & $2.9(6.03)$ & -2.4 & $\mathrm{P}<.00 \mathrm{I}$ & 0.285 \\
\hline Trait Anger-Temperament & $2.4(3.09)$ & $1.9(2.57)$ & -0.5 & $\mathrm{P}<.00 \mathrm{I}$ & 0.228 \\
\hline Trait Anger-Reaction & $2.7(2.73)$ & $2.2(2.47)$ & -0.5 & $\mathrm{P}<.00 \mathrm{I}$ & 0.231 \\
\hline Trait Anger-Expression Out & $7.2(4.85)$ & $6.5(4.53)$ & -0.6 & $\mathrm{P}<.00 \mathrm{I}$ & 0.163 \\
\hline Trait Anger-Expression In & $9.4(4.82)$ & $8.6(4.84)$ & -0.9 & $\mathrm{P}<.001$ & 0.179 \\
\hline Trait Anger-Control Out & $12.8(5.93)$ & I3.2(5.94) & 0.4 & $\mathrm{P}<.06 \mathrm{I}$ & 0.072 \\
\hline Trait Anger-Control In & $13.3(6.46)$ & I $3.7(6.54)$ & 0.4 & $\mathrm{P}<.056$ & 0.073 \\
\hline Trait Anger Composite Score & $6.6(6.49)$ & $5.2(5.70)$ & -1.4 & $\mathrm{P}<.00 \mathrm{I}$ & 0.272 \\
\hline \multicolumn{6}{|l|}{ Anger Representation } \\
\hline Instrumental Anger Score & $17.6(7.89)$ & I5.8 (7.29) & -1.8 & $\mathrm{P}<.00 \mathrm{I}$ & 0.284 \\
\hline Expressive Anger Score & $23.5(7.45)$ & $22.0(7.57)$ & -1.5 & $\mathrm{P}<.00 \mathrm{I}$ & 0.198 \\
\hline \multicolumn{6}{|l|}{ Empathy } \\
\hline Perspective Taking & $25.2(5.56)$ & $25.6(5.95)$ & 0.3 & $\mathrm{p}<.108$ & 0.062 \\
\hline Lack of Empathic Concern & $27.3(5.22)$ & $26.9(5.49)$ & -0.4 & $\mathrm{P}<.033$ & 0.083 \\
\hline Social Connectedness & $3.9(0.93)$ & $4.1(0.94)$ & 0.2 & $\mathrm{P}<.00 \mathrm{I}$ & 0.216 \\
\hline \multicolumn{6}{|l|}{ Emotional Regulation } \\
\hline Non-Acceptance & $14.9(6.07)$ & I $3.9(5.89)$ & -1.1 & $\mathrm{P}<.00 \mathrm{I}$ & 0.186 \\
\hline Goals & I $4.3(4.76)$ & I2.9 (4.7I) & -1.4 & $\mathrm{p}<.001$ & 0.321 \\
\hline
\end{tabular}

Citation: Messina N, Zwart E. Breaking the Silence and Healing Trauma for Incarcerated Women: Peer-facilitated Delivery of a Brief Intervention. MOJWomen's Health. 202I;I0(I):8-16. DOI: 10.15406/mojwh.202I.10.00280 
Table Continued.

\begin{tabular}{|c|c|c|c|c|c|}
\hline Description & Pre-Program Mean (SD) & Post-Program Mean (SD) & Change & Sig. & Cohen's d \\
\hline Impulse & $\mid 4.0(5.6 \mid)$ & $12.8(5.26)$ & -1.2 & $\mathrm{P}<.001$ & 0.274 \\
\hline Awareness & |4.0 (5.4I) & I 3.5 (5.49) & -0.5 & $p<.014$ & 0.096 \\
\hline Strategies & I8.6 (6.7I) & I7.0 (6.36) & -1.6 & $\mathrm{P}<.001$ & 0.291 \\
\hline Clarity & II.3 (4.24) & II.0 (4.2I) & -0.3 & $\mathrm{P}<.014$ & 0.097 \\
\hline
\end{tabular}

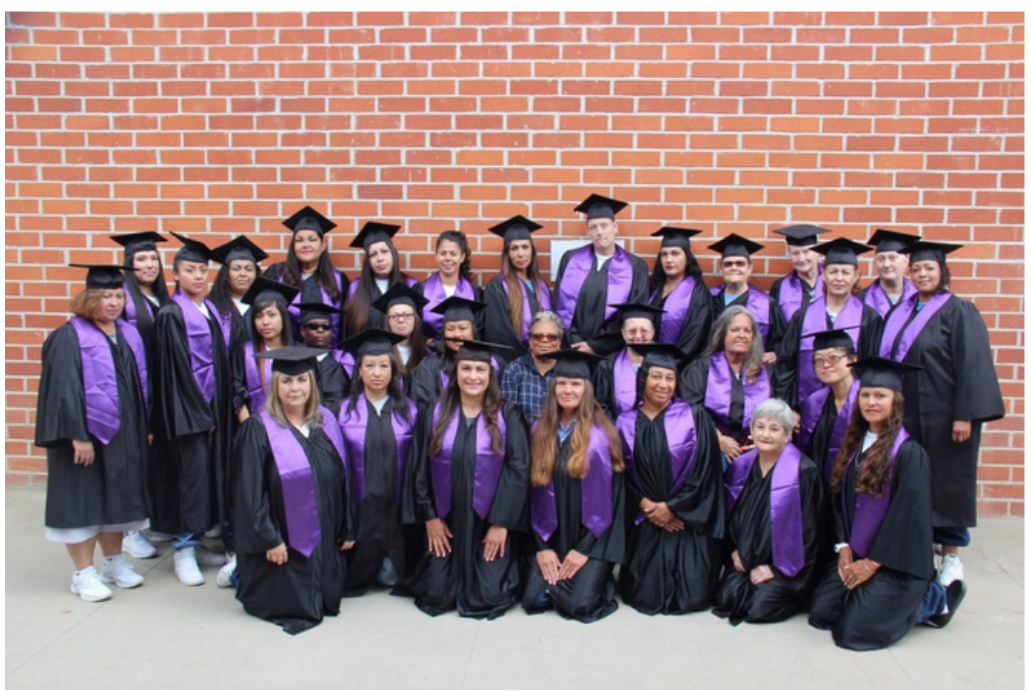

\section{Discussion}

The study results have demonstrated the feasibility and efficacy of delivering a gender-responsive and trauma-specific brief intervention for incarcerated women. Moreover, the results show that a peerfacilitated model of program delivery can be significantly impactful for justice-involved women to reduce trauma-related difficulties and increase well-being. The $H T$ brief intervention could be effectively used to introduce participants in short-term housing to new skills that help them deal with psychological trauma, build healthy relationships and sustain their recovery. The current results replicate the positive findings from the previous pilot study of security housing participants. $^{20}$

The demographic findings further substantiate the existing literature outlining the high prevalence of multiple complex problems among incarcerated women (e.g., childhood trauma, violence, victimization, and adult mental health problems). In fact, the sample of women in this study reported extensive histories of ACEs, household dysfunction, early criminal justice involvement, frequent drug and alcohol use prior to incarceration, continued violence and victimization as adults, and ongoing mental health challenges. The positive post-intervention change indicates that there is potential for effective peer-facilitated, trauma-specific program services to be more broadly implemented in corrections.

\section{Limitations}

The study is limited in that we used a single group pretest-posttest design and did not include a comparison group of women who did not participate in $H T$. Therefore, it is difficult to judge whether improvements in posttest measures were indeed solely a product of participation in the curriculum. However, the findings are consistent with more rigorous evaluations of trauma-specific and genderresponsive program studies with women in prisons in California ${ }^{41,43}$ and in Michigan. ${ }^{42,45}$
Additionally, the current study relied on self-administered survey data. We did not have access to objective measures (i.e., records-based data) to determine previous mental health diagnoses or to substantiate self-reported histories of crime and addiction. The questions on the ACE survey were also limited, as the results regarding histories of abuse were dichotomous (yes or no) questions, which did not inquire about the perpetrator(s) of the abuse, the age at which it occurred, or the duration of the abuse. Thus, responses to the questions reflected each respondent's interpretation of the questions, including those regarding physical and sexual assault. There is also the potential for a biased estimation resulting from sample attrition. However comparisons between those lost at follow-up did not show significant differences compared with those who completed the follow up surveys.

\section{Strengths}

The $H T$ program curriculum is a manualized intervention providing both a detailed facilitator guide and a participant workbook. The use of a manualized curricula creates the ability to monitor fidelity of peer-facilitation. Peer-facilitators had been trained by the program author, enhancing fidelity of the program facilitation. Additionally, the program and peer-facilitators had oversight from a Program Coordinator, also trained by the $H T$ author. The $H T$ program also uses a variety of therapeutic approaches to address the impact of trauma: CBT, expressive arts, mindfulness, and guided imagery. It is also gender responsive in that it reflects an understanding of the realities of women's lives and its theoretical basis is centered on women's psychological development. Finally, the $H T$ content was created to specifically address justice-involved women's needs, such as learning styles, motivation, abilities, and strengths.

The $H T$ program continues to operate in both facilities after the pilot study ended and has been expanded to other prisons in California. Based on the positive results of the evaluation, the $H T$ program has also been modified to meet the needs of gender minority populations (e.g., transgender, nonbinary) populations. The CDCR further participated 
in the expansion of the male version of the trauma-specific brief intervention in the general population at five other male facilities in California (Exploring Trauma: A Brief Intervention for Men). ${ }^{60}$

Brief trauma-specific therapies can be used to effect significant changes in participants' behaviors and their understanding of the lifelong impact of ACEs. Additionally, brief trauma-specific interventions can be used as a method of providing more immediate attention to clients on waiting lists for specialized programs and motivating an individual to begin to focus on behavior change by client directed means or by seeking additional treatment.

The pilot study findings provide a knowledgebase to create larger more rigorous studies, which can ultimately determine the efficacy of trauma-specific programming services for incarcerated women and identify effective program delivery models. The findings may be applicable to corrections services as they indicate the efficacy of brief interventions as well as peer-facilitated interventions. However, this study underscores the need for appropriate peer training, oversight, and manualized curricula to enhance fidelity and reliability of the program facilitation. Future studies should implement experimental methods with other populations of women in various states across the nation, as incarcerated populations in California may not be generalizable to other states. ${ }^{61,62}$

\section{Acknowledgments}

This pilot project would not have been possible without the strong support and engagement of the California Department of Corrections and Rehabilitation (CDCR) Lead Administrators such as former FOPS Directors, Jay Virbel and Amy Miller, the Director and Deputy Director of the Department of Rehabilitative Programming, Brantley Choate and Kevin Hoffman, and the institutional staff at the California Institution for Women (CIW) and the Central California Women's Facility (CCWF). We are especially grateful to Dr. Stephanie Covington, the author of the trauma-specific program for women, Healing Trauma: A Brief Intervention for Women. Dr. Covington's dedication to enhancing the wellbeing of incarcerated women around the world is demonstrated in her collective publication and gender-responsive curriculum development. We would also like to acknowledge retired Captain Rochelle Leonard and retired Chief Deputy Warden Velda Dobson-Davis for their unwavering dedication, coordination, and oversite of the peer-facilitated brief interventions at the facilities. We are also grateful for the peers who volunteered to participate in the training and facilitation of this program to other women. We would also like to thank the Research Director Dr. Stacy Calhoun and her research assistant, Claire Samuelson. We are grateful for CDCR's continued support of the program, graduations, and ongoing navigation of the program in a difficult environment. Finally, we are indebted to the women who so kindly volunteered their time, insights, and reflections from participating in Healing Trauma to this project.

\section{Conflicts of interest}

The author declares that there is no conflict of interest to disclose.

\section{Funding}

The funding for the pilot project was provided via a contract between the California Department of Corrections and Rehabilitation, Long Term Inmate Programming Grants with Envisioning Justice Solutions, Inc. (EJS) under grant \#C5606920 and \#C5606916. EJS entered into a subcontract with the Center for Gender and Justice to conduct the program training and fidelity monitoring of the program. EJS conducted the evaluation component of the pilot study.

\section{References}

1. Covington SS, Russo R. Healing Trauma: A brief intervention for women CD-Rom. Center City, MN: Hazelden. (2011, rev 2016).

2. Block CR, Blokland AAJ, Van der Werff C, et al. Long-term patterns of offending in women. Feminist Criminology. 2010;5(1):73-107.

3. Cauffman EE. Understanding the female offender. Future Child. 2008;18(2):119-142.

4. Grella C, Stein J, Greenwell L. Associations among childhood trauma, adolescent problem behaviors, and adverse adult outcomes in substanceabusing women offenders. Psychol Addict Behav. 2005;19(1):43-53.

5. Reisig MD, Holtfreter K, Morash M. Assessing Recidivism Risk Across Female Pathways to Crime. Justice Quarterly. 2006;23(3):384-405.

6. Messina N, Grella C. Childhood trauma and women's health outcomes in a California prison population. Am J Public Health. 2006;96(10):18421848 .

7. Messina N, Burdon W, Hagopian G, et al. One year return to custody rates among co-disordered offenders. Behav Sci Law. 2004;22(4):503-518.

8. Messina N, Grella C, Burdon W, et al. Childhood adverse events and current traumatic distress: A comparison of men and women prisoners. Criminal Justice and Behavior. 2007;34(11):1385-1401.

9. Babcock JC, Miller SA, Siard C. Toward a typology of abusive women: Differences between partner-only and generally violent women in the use of violence. Psychology of Women Quarterly. 2003;27(2):153-161.

10. Kruttschnitt C, Gartner R, Ferraro K. Women's involvement in serious interpersonal violence. Aggression and Violent Behavior:2002;7(6):529-565.

11. Kubiak SP, Fedock G, Kim WJ, et al. Examining perpetration of physical violence by women: The influence of childhood adversity, victimization, mental illness, substance abuse, and anger. Violence Vict. 2017;32(1):2245 .

12. Saxena P, Messina, N. Perpetration of abuse and early criminal justice involvement among incarcerated women. (under review).

13. Owen BA. "In the Mix": Struggles and Survival in a Women's Prison. United States: State University of New York Press. 1998.

14. Owen B, Wells J, Pollack J. "In Search of safety": Confronting inequality in women's imprisonment. University of California Press: Oakland, California. 2017.

15. Covington S. Helping Women Recover: A program for treating addiction (3rd.ed.). Hoboken, NJ: Wiley. 2019.

16. Covington S, Griffin D, Dauer R. Helping Men Recover: A program for treating addiction. Hoboken, NJ: Wiley. 2011.

17. Messina N, Braithwaite J, Calhoun S, et al. Examination of a violence prevention program for serious female offenders. Violence and Gender. 2016;3(3):143-149.

18. Saxena P, Messina M, Grella C. Who benefits from gender responsive treatment? Accounting for abuse history on longitudinal outcomes for women in prison. Crim Justice Behav. 2014;41(4):417-432.

19. Messina N, Burdon W. The efficacy of the Moving Beyond Violence and Building Resilience Program: Final report. California Department of Corrections and Rehabilitation, July. 2018.

20. Messina N, Zwart E, Calhoun S. Efficacy of a trauma intervention for women in a security housing unit. ARCH Women Health Care .2020;3(3): $1-9$. 
21. SAMHSA. SAMHSA's Concept of Trauma and Guidance for a TraumaInformed Approach SAMHSA's Trauma and Justice Strategic Initiative. 2014.

22. Joe GW, Knight K, Simpson DD, et al. An evaluation of six brief interventions that target drug-related problems in correctional populations. J Offender Rehabil. 2012;51(1-2): 9-33.

23. Petosa RL, Laureen HS. Peer Mentoring for Health Behavior Change: A Systematic Review. American Journal of Health Education. 2014;45(6):351-357.

24. Rhodes Jean E, Ranjini R, Jean BG. The protective influence of mentoring on adolescents' substance use: Direct and indirect pathways. Applied Developmental Science. 2005;9(1):31-47.

25. Tolan PH, Henry D, Schoeny M. Mentoring interventions to affect juvenile delinquency and associated problems. Campbell Systematic Review. 2008;16:1-112.

26. Bagnall AM, South J, Hulme C, et al. A systematic review of the effectiveness and cost-effectiveness of peer education and peer support in prisons. BMC Public Health. 2015;15:290.

27. Devilly GJ, Sorbello L, Eccleston L. Prison-based peer-education schemes. Aggression and Violent Behavior. 2005;10(2):219-40.

28. Woodall J, South J, Dixey R, et al. Expert views of peer-based interventions for prisoner health. Int J Prison Health. 2015;11(2):87-97.

29. South J, Bagnall AM, Hulme C, et al. A systematic review of the effectiveness and cost-effectiveness of peer-based interventions to maintain and improve offender health in prison settings. Health Services and Delivery Research. 2014;2(35).

30. Herman JL. Complex PTSD: A syndrome in survivors of prolonger and repeated trauma. Journal of Traumatic Stress. 1992;5:377-391.

31. Herman JL. Trauma and recovery. New York, NY: Basic Books. 1997.

32. Kendall Tackett KA. Physiological correlates of childhood abuse: Chronic hyperarousal in PTSD, depression, and irritable bowel syndrome. Child Abuse Negl. 2000;24(6):799-810

33. Greenfield EA, Marks NF. Identifying experiences of physical and psychological violence in childhood that jeopardize mental health in adulthood. Child Abuse Negl. 2010:34(3):161-171.

34. Mechanic MB, Weaver TL, Resick PA. Mental health consequences of intimate partner abuse: A multidimensional assessment of four different forms of abuse. Violence Against Women, 2008;14(6):634-654.

35. Hedtke KA, Ruggiero KJ, Fitzgerald MM, et al. A longitudina investigation of interpersonal violence in relation to mental health and substance use. J Consult Clin Psychol. 2008;76(4):633-647.

36. Najavits LM, Weiss RD, Shaw SR. The link between substance abuse and posttraumatic stress disorder in women: A research review. Am J Addict. 1997;6(4):273-283.

37. Neumann DA, Houskamp BM, Pollock VE, et al. The long-term sequelae of childhood sexual abuse in women: A meta-analytic review. Child Maltreatment. 1995;1(1):6-16.

38. Newman AL, Peterson C. Anger of women incest survivors. Sex Roles. 1996;34:463-474.

39. Springer KW, Sheridan J, Kuo D, et al. Long-term physical and mental health consequences of childhood physical abuse: Results from a large population-based sample of men and women. Child Abuse Negl. 2007;31(5):517-530.

40. Thomas PM. Dissociation and internal models of protection: Psychotherapy with child abuse survivors. Psychotherapy: Theory, Research, Practice, Training. 2005;42(1):20-36.

41. Messina N, Grella C, Cartier J, et al. A randomized experimental study of gender responsive substance abuse treatment for women in prison. $J$ Subst Abuse Treat. 2010;38(2):97-107.
42. Kubiak SP, Fedock G, Tillander E, et al. Testing a violence-prevention intervention for incarcerated women using a randomized control trial. Research on Social Work Practice. 2014a;1 - 15.

43. Messina N, Calhoun S, Braithwaite J. Trauma-informed treatment decreases posttraumatic stress disorder among women offenders. $J$ Trauma Dissociation. 2014.;5(1):6-23.

44. Kubiak SP, Fedock G, Tillander E. Assessing the feasibility and fidelity of an intervention for women with violent offenses. Eval Program Plann. (2014b);42:1-10.

45. Kroenke K, Spitzer RL. The PHQ-9: A new depression diagnostic and severity measure. Psychiatric Annals. 2002;32(9):509-515

46. Spitzer RL, Kroenke K, Williams JB. Patient Health Questionnaire Primary Care Study Group: Validation and utility of a self-report version of PRIME-MD: the PHQ primary care study. JAMA. 1999;282(18):17371744.

47. Breslau N, Peterson EL, Kessler RC, et al. Short screening scale for DSMIV posttraumatic stress disorder. Am J Psychiatry. 1999;156(6): 908-911.

48. Kessler RC, Andrews G, Colpe LJ, et al. Short screening scales to monitor population prevalences and trends in non-specific psychological distress. Psychol Med. 2002;32(6):959-976.

49. Kessler RC, Barker PR, Colpe LJ, et al. Screening for serious mental illness in the general population. Arch Gen Psychiatry. 2003;60(2):184 189.

50. Buss AH, Warren WL. The Aggression Questionnaire Manual. Los Angeles: Western Psychological Services. 2000.

51. Spielberger CD. STAXI-2: State-Trait Anger Expression Inventory - 2. Professional manual. Odessa, FL: Psychological Assessment Resources. 1999.

52. Campbell A, Muncer S, McManus IC, et al. Instrumental and expressive representations of aggression: One scale or two? Aggressive Behavior 1999;26(6):435-444.

53. Sinclair VG. Wallston KA. The development and psychometric evaluation of the Brief Resilient Coping Scale. Assessment. 200;11(1):94-101.

54. Davis MH. A multidimensional approach to individual differences in empathy. JSAS Catalog of Selected Documents in Psychology. 1980;10:85.

55. Davis MH. Measuring individual differences in empathy: Evidence for multidimensional approach. Journal of Personality and Social Psychology. 1983;44(1):113-126.

56. Lee RM, Draper M, Lee S. Social connectedness, dysfunctional interpersonal behaviors, and psychological distress: Testing a mediator model. Journal of Counseling Psychology. 2001;48(3):310-318.

57. Lee RM, Robbins SB. Measuring belongingness: The Social Connectedness and the Social Assurance Scales. Journal of Counseling Psychology. 1995;42(2):232-241.

58. Lee RM, Draper M, Sujin L. Social connectedness, dysfunctional interpersonal behaviors, and psychological distress: Testing a mediator model. Journal of Counseling Psychology. 2001;48(3):310-318

59. Sullivan GM, Feinn R. Using Effect Size-or Why the P Value Is Not Enough. J Grad Med Educ. 2012;4(3):279-282.

60. Covington S, Rodriguez R. Exploring Trauma: A brief intervention for men. Center city, MN: Hazelden; 2016.

61. Messina N, Calhoun S. A randomized controlled trial assessing the Beyond Violence Program: Final report. The National Institute of Corrections, Office of Violence Against Women, October. 2019.

62. Messina N, Calhoun S. Healing Trauma: Final report. The California Department of Corrections and Rehabilitation, July. 2018. 